\title{
PRINCIPLES OF FORMATION OF RESEARCH AND EDUCATIONAL OBJECTS OF INNOVATIVE PURPOSE
}

\author{
Andrey Pozdnyakov ${ }^{1 *}$, Ekaterina Pozdnyakova ${ }^{1}$, Carlos Marmolejo ${ }^{2}$ \\ Southwest State University, Kursk, Russian Federation \\ Polytechnic University of Catalonia, Barcelona, Spain
}

An analysis of global trends in the development of education and science shows that a modern university has ceased to be a place for transferring knowledge from a teacher to a student in the form of lectures. Today, the university fulfills the task of forming intelligence in the form of knowledge, innovation, competencies, being at the same time a space for researchers, teachers, and students to meet and work together. This article discusses the main functional components of modern Research and Educational objects. The analysis revealed a common unifying link in the relationship of these blocks. The result of studying domestic and foreign experience in the design and construction of educational centers was the identification of the basic principles of their formation.

Key words: university design, educational facilities, research and educational centers

\section{INTRODUCTION}

The priority in the socio-economic policy of the leading countries is to ensure a high quality of life for the population, which at the same time attracts the best professionals from all over the world. In modern conditions, leading universities in all countries are becoming catalysts of economic growth based on innovation, centers of social and cultural life in the region, a connecting element between society, government and the business community. The combination of research and educational activities in university complexes provides practicality and competitive advantages of educational technologies and new staff compared to traditional universities. These universities form the human resources potential for innovative areas in science and business [1].

New educational technologies undoubtedly require new spaces and new architectural forms for their full deployment. In such circumstances, it is extremely necessary to develop new concepts of Russian University complexes based on the world experience in designing and building universities and research and educational centers.

To understand the spatial structure and prospects for the development of University spatial forms, it is necessary to understand their history and global trends that exist at present, as well as to study the main promising models for the development of higher education institutions that work effectively in different countries. The analysis of advanced international and domestic experience in the design and construction of scientific and educational facilities made it possible to formulate the basic principles of architectural and planning formation of these objects.

\section{FUNCTIONAL ORGANIZATION OF OBJECTS OF EDUCATION}

The architectural and spatial formation of scientific and innovative objects follows the laws common to modern buildings of public, scientific and industrial purposes. However, some provisions are distinctive, highlighting the subject of study in a separate, complex object of design. It is these features that underlie the basic principles of the formation of the architectural and planning structure and assess the effectiveness of design decisions of Research and Educational objects [2].

At the beginning, it is necessary to define the Research and Educational Center (REC) as a new typological unit of the University complex, which differs from the classic academic building of the University of the last century.

The Research and Educational Center is primarily a multi-functional structure that includes various rooms. Their association "under one roof" gives a synergistic effect in the process of training and research [3].

The principal components of a new generation Research and Educational Center, or functional groups of spaces, are:

Learning spaces that take into account the specifics of the educational process and technologies. In accordance with the new learning paradigm, they should include:

- rooms for individual classes of students and consultations (for 1-5 people), small auditoriums (up to 20 people);

- seminar rooms (up to 50 people);

- shared transformable audiences for streaming groups (up to 80-150 people);

- computer rooms for distance learning, video bridges, etc. (up to 30 people),

- multifunctional transformable rooms;

- special classrooms that are designed depending on the specifics of the educational process (language laboratories, etc.).

- rooms for individual work of teachers and professors 
(for 1 person) and rooms for collective work of teachers (free layout, rooms with a capacity of up to 20 people).

Spaces for scientific activity.

In this group of REC spaces you can allocate premises that are associated with the organization of scientific and innovative activities of the center, they must take into account the specifics of the process and the necessary equipment. Typologically, these spaces can be divided into:

- laboratories (from 3 to 20 people);

- experimental production facilities. Their spatial characteristics, as well as their technical requirements, can vary very widely depending on the type of technology being designed (for example, for a nuclear center and a medical training center);

- rooms for seminars and negotiations (from 5 to 20 people);

- offices of researchers, heads of departments, postgraduates and doctoral students, as well as common rooms for formal and informal events.

Spaces for scientific and organizational activities. This functional group can include:

- halls for events (for example, the hall of the academic Council for the defense of dissertations for 100 people);

- information centers for remote monitoring and training, local libraries and storage facilities.

Administrative premise.

- Executive offices, offices, meeting rooms;

- technical premises for ensuring the functioning and operation of the building;

- catering facilities (restaurants, buffets, canteens, cafes with their offices) and a group of premises for major cultural and communication events;

- conference halls (up to 300-500 people), Congress halls (from 500 people) [4].

These rooms can be transformed. In addition to these basic functional units the REC should have halls, communication and recreational spaces such as covered courtyards, internal gardens, technical rooms, and corridors.

In addition, in successful and effective research and educational centers in the architectural and spatial sense, there must be some semantic recreational and communication space, which is the unifying principle. This can be a hall space with a main conference hall, a multi-level exhibition hall, etc.

\section{PRINCIPLES OF FORMATION OF RESEARCH AND EDUCATIONAL CENTERS}

Based on a functional analysis of the recently built research and educational centers of some universities, the principles of designing and building university research and educational centers were formulated:

1. The principle of cases. Since research and educational centers must comply with the new concept of teaching, in most classrooms and classrooms, the use of case studies in classes should be taken into account. Audiences of 20-50 people occupy 60-70 percent of the training area, and laboratories and workshops - more than 50 percent of the entire center. In this case, it is possible both to divide these rooms into blocks, and to mix them according to levels or adjacent spaces (depending on the specifics of the scientific and educational process).

2. The principle of transformation. One of the main elements of constructing the spatial structure of a modern Research and Educational Center is a transformable space and a free plan, which involves the use of a post-beam system or a monolithic frame structure. This allows you to change the number, capacity and structure of spaces. In this case, engineering communications for the most part pass through the floor and ceiling in special engineering channels, which makes it possible to redevelop with the connection of the necessary technical devices in each cell of the building (for example, 6 by 6 meters in size) [5].

3. The principle of functional separation. Dividing into functional levels is more effective in terms of communications and connections between rooms and in terms of rational use of space and sustainable development. This approach is superior to the block principle of design, especially with a shortage of territory.

4. The principle of adaptation. The reserves for the development and transformation of the complexes are very important, since the Research and Educational Center is not only and not so much a building as changing educational programs and technologies. In the future, when they change, new premises and territories will be required, therefore, the task of possible expansion should be laid down already at the initial design stage.

5. The principle of environmental friendliness. Ecology and energy conservation is one of the main trends in modern construction, which fits into the environmental concept of advanced university campuses. New buildings should strive to meet LEED and BREEAM standards. Modern "eco-creation" involves the maximum use of sunlight and solar energy, as well as any other renewable energy sources. Also, water, air, waste disposal systems, gas turbines, etc. are used, a special policy is envisaged in relation to rain, snow, a concept is being developed to maintain an ecological balance in emissions and cleaning of the territory $[6,9]$.

6. The principle of context. According to the main trends in the design of university campuses, whose programs for the most part involve "context and fit" into the natural environment, rather than creating an analogue of the urban quarter space, REC buildings 
do not form urban development, but dissolve in the environment. It should be noted comfortable and vivid landscaping of territories and interior spaces using the existing landscape. All this ultimately creates a complex of "green campus", which forms a special atmosphere of work and study [7].

Research and Educational Centersas mixed buildings deserve special attention, which make it possible to combine different disciplines in one spatial block, for example, combining the functions of nuclear energy and medical research, which leads to synergy in research programs, allowing you to create new technologies in breakthrough areas. This corresponds to the main principle of the REC - complexity, in which the combination of educational, scientific and educational spaces, and in various disciplines, with the possibility of transforming the program for using these spaces, gives greater freedom in educational and scientific processes [8].

\section{CONCLUSION}

New typological groups of spaces and structures that are created on modern and old campuses of world universities form the main spatial and architectural-shaped structure of the university campus. These objects are the basic functional units of the university complex, a change in their structure reflects the transformation of the educational process, their appearance expresses the basic ideas and forms the spatial and figurative "identity" of the university. Under certain conditions such an identity can become a catalyst for the research process, attracting specialists and researchers.

\section{ACKNOWLEDGEMENT}

Author thanks the Rector of the Southwest State University, Doctor of Technical Sciences Yemelyanov S.G.

\section{REFERENCES}

1. Dianova-Klokova, I.V. (2012) The space of innovation - issues of architectural design. Architecture and Construction of Russia, No. 6, Pp.3-19

2. Dianova-Klokova, I.V., Metaniev, D.A. (2016) Social engineering in the architecture of scientific and innovative facilities Academia. Architecture and Buildings, No. 2. Pp. 71-78.

3. Dobretsov, N.A. (2003) Scientific schools of the Academy of Sciences as a tool for maintaining and replenishing scientific potential. Science of Science. No. 1, P.78.

4. Puchkov, M.V. (2011) The principles of designing a new generation of scientific and educational centers: the architecture of modern teaching technologies. Academia. Architecture and Construction. No. 2, Pp. 48-51.

5. Leonidovich, P. A., Viktorovna, P. E., \& Vladimirovna, O. A. [2019]. A retrospective analysis of the interrelated development of science and higher education in the world. Journal of Applied Engineering Science, 17(4), 463-467.

6. Gennadievna-Pahomova, E., Tomakov, I. V., \& Tomakov, V. M. [2017]. The formation of the green building market of the Russian cities. Journal of Applied Engineering Science, 15(3), 395-400.

7. Antonov, A.V. (2007) Principles of building architecture of buildings of innovation centers. $30 \mathrm{pp}$.

8. Brundukova, V.A., Denisenko E.V. (2018) Principles of the formation of educational centers. Proceedings of KSASU, No. 3, Pp. 81-87.

9. Khaustov, V., Kruglova, L., Bredikhina, N., \& Guseinov, T. [2019]. The impact of flooding on the operational reliability of real estate in the Kursk region. Journal of Applied Engineering Science, 17(2), 213-216.

Paper submitted: 27.04.2020.

Paper accepted: 29.05.2020.

This is an open access article distributed under the CC $B Y-N C-N D 4.0$ terms and conditions. 